stances, small in amount, became of prime importance in dietetics, and we know to-day how much our health and well-being depend on these accessory food substances.

Atomic physics might be taken as a second example of a branch of science where not many years ago all problems appeared to have been solved and every. thing to be known. We have only to look back at the last thirty years to realize how very limited our outlook really was in those days.

Human colour perception to-day is in a similar situation, because, until quite recently, most-if not all-known visual phenomena were adequately accounted for either on the three-colour theory of Thomas Young or on the four-colour theory of Ewald Hering. But we are beginning to suspect that things are not quite so simple as they seemed and that there may be present in the human retina certain accessory receptor mechanisms, not embraced by either of these theories, which, however, play an important part in man's colour sense. The questions which now confront us are similar to those which claimed the attention of the early workers on the vitamins.

So far as present evidence goes, there appear to be four additional types of receptor, three of which have a single maximum of activity in the spectrum, which is situated in the yellow, in the blue-green or in the blue. The fourth has two regions of activity : in the extreme red and in the extreme violet; and for this reason may be referred to as "the crimson receptor' mechanism. These four accessory mechanisms, which play a relatively unimportant part in foveal vision at medium visual angles and at medium light intensities, hold a very different position when these conditions are departed from. Thus in the dichromatic zone of the retinal periphery, at medium light intensities and at the fovea at very high intensities, two of these subsidiary receptor systems, the yellow and the blue, hold a predominant position. On the other hand, at very low light intensities and at very small visual angles, the two receptor types which are most strongly represented are the crimson and the blue-green.

While nearly every phase of human colour perception, when closely examined, discloses evidence of the presence of these supplementary receptors, the idea that there are four of them, or that they have the properties preliminarily assigned to them, may have to be modified in important respects as additional knowledge is acquired.

Lessons of a valuable kind are to be learned from a study of the history of the vitamins; because, whereas only a few years ago a few appeared to suffice, we now have overwhelming evidence that there are many. So it may be with the visual receptors. At this juncture the important point is for us to recognize that accessory receptors are present in the human retina, and then to concentrate attention on the wider problems which their presence involves.

\section{PRESENT-DAY TRENDS IN BRITISH PSYCHOLOGY}

$\mathrm{P}^{\mathrm{R}}$ ROF. REX KNIGHT, in his presidential address to Section J, remarks that more than sixty years have now passed since the "Encyclopædia Britannica" first published in $\mathbf{1 8 8 6}$ Ward's famous article on
"Psychology", which William James at once described as "marking the transition of British psychology from one epoch to another'. Ward's article showed that psychology was no longer to be regarded as a branch of analytic or speculative philosophy, but as a positive science concerned with the systematic investigation of matters of fact. Since it appeared, striking changes have occurred in the scope, methods and practical usefulness of psychology in Great Britain.

In scope, there have been five major developments. First, physiological psychology, which everyone except Bain neglected in the 'eighties, has come into its own. This has been due to the advocacy of Sully and James, the general acceptance of the evolutionary theory, the researches of neurologists like Lashley and Sherrington, and the influence of the behaviour. ists.

Secondly, psychology is no longer preoccupied with cognition. The work of James, MeDougall and Freud has developed an intense interest in dynamic psychology, and at least as much attention is now given to the conscious and unconscious motives that underlie thought and behaviour as to the processes which are involved in the acquisition of knowledge itself.

Thirdly, sixty years ago psychologists concerned themselves mainly with human beings, and with human beings who were adult, civilized and normal. Now animal psychology, child psychology, anthrop. ological psychology and abnormal psychology are all prominent features of the psychological landscape, and are receiving much attention.

Fourthly, psychology was generally regarded in 1886 as the study of man as an isolated individual, whereas present-day psychology is much concerned with man as a member of society.

Fifthly, the last sixty years have seen the de. velopment of mental tests, which, though originated by Galton before Ward's article appeared in the "Encyclopædia Britannica", have been developed during the present century in Britain chiefly by Spearman, Thomson and Burt.

In method, there have also been five notable changes. First, introspection, which dominated the field in 1886, has been supplemented by observation of behaviour and exploration of the unconscious. Secondly, experimental psychology, which was dis. paraged by most nineteenth-century British psy. chologists, has established itself. Thirdly, the anec. dotal method, once so common in psychology as well as biology, is under sentence of banishment. Fourthly, field-studies have become as important as laboratory investigations. Fifthly, the statistical principles and techniques appropriate to psychological data havo received great attention.

In practical usefulness, psychology in Britain has moved during the period under review from a stage where applied psychology was almost unknown to one where psychology is eonstantly being applied to the practical problems of public and private life. Educational psychology is now an important ingred. ient in the training of teachers, and educational psychologists are becoming established members of the staffs of education authorities. Psychiatry is a recognized branch of medicine, and clinical psycholog. ists are employed in many fields. Occupational or industrial psychology, the development of which in Great Britain owed so much to Charles Myers, was used on a large scale in the Second World War, and is now being used in the drive for greater productivity. 